\title{
Membangkitkan kesadaran beragama resident/clien dalam proses rehabilitasi di Yayasan Rumah Ummi di Kecamatan Medan Sunggal Kota Medan
}

\author{
Nelvitia Purba*, Sri Sulistyawaty, dan Ahmad Darwis \\ Universitas Muslim Nusantara Al Washliyah Medan \\ * nelvitiapurbaumn@gmail.com
}

\begin{abstract}
Abstrak. Penyalahgunaan dan peredaran Narkoba di Kota Medan akhir-akhir sangat memprihatinkan, hampir semua kalangan adalah merupakan sasaran, terutama remaja dan anak muda, Narkoba termasuk kejahatan yang luar biasa (ekstra ordinary crime) yang sangat merusak daripada fisik dan mental dari pada generasi penerus bangsa tersebut. Oleh karena itu diperlukan pusat rehabilitasi yang memenuhi standar. Rehabilitasi merupakan upaya memulihkan dan mengembalikan kondisi korban dan penyalah gunaan narkoba agar kembali sehat secara fisik, psikologik, sosial dan spiritual. Selama ini kegiatan spiritual Pusat rehabilitasi Rumah Ummi masih belum optimal. Metode Kegiatan antara lain: Kegiatan ceramah,pengajian dan dilanjutkan dengan kegiatan praktek ibadah yang langsung dibimbing oleh salah satu dosen Tim Program Kemitraan Stimulus (PKMS) UMN Al Washliyah Medan Dosen Pendidikan Agama Islam yang juga merupakan ustad. Hasil dari Program Kegiatan ini kepada Clien/Pasien yang Direhabilitasi menjadi kondisi yang sehat dan mampu kembali berfungsi secara normal dalam kehidupan sehari-hari. Dan tidak kembali lagi menggunakan Narkoba tersebut.
\end{abstract}

Kata kunci: membangkitkan; rehabilitasi; kesadaran beragama; kondisi sehat

\begin{abstract}
The abuse and distribution of narcotics in the city of Medan have been very worrying lately, almost all groups are the target, especially teenagers and young people, Narcotics include extraordinary crimes (extraordinary crime) that are very destructive than physical and mental than the next generation of the nation. Therefore a rehabilitation center that meets standards is needed. Rehabilitation is an effort to restore and restore the condition of victims and drug abuse to return to physical, psychological, social and spiritual health. So far the Ummi House rehabilitation center has not been optimal. The method of this routine activity is: Every morning wake up, the residents/clients are obliged to carry out morning prayers in congregation and prayer five times, holding recitals. For this reason, a Chancellor and Worship Practice program is required and other activities are closed at $10 \mathrm{pm}$. There is no time left, all the time utilized in the framework of resident recovery. The results of this Activity Program to Clients / Rehabilitated Patients are a healthy condition and can return to normal functioning in daily life. And do not return to using the Drug.
\end{abstract}

Keywords: generating; rehabilitating; religious awareness; healthy conditions

To cite this article: Purba, N., S. Sulistyawaty, \& A. Darwis. 2019. Membangkitkan Kesadaran Beragama Resident/Clien dalam Proses Rehabilitasi di Yayasan Rumah Ummi di Kecamatan Medan Sunggal Kota Medan. Unri Conference Series: Community Engagement 1: 69-73. https://doi.org/10.31258/unricsce.1.69-73

(C) 2019 Authors

Peer-review under responsibility of the organizing committee of Seminar Nasional Pemberdayaan Masyarakat 2019 


\section{PENDAHULUAN}

Peredaran Narkoba di kalangan remaja Indonesia kian meresahkan, jumlah penggunaan mengalami peningkatan yang cukup tajam Sumatera Utara pata tahun 2016 terdapat 5,9 juta anak yang menjadi pecandu Narkoba sedangkan pada tahun 20154.9 juta anak yang menjadi pecandu Narkoba.Peran rehabilitasi dalam penyembuhan ketergantungan bagi pecandu Narkoba sangat penting, karena semakin bertambah pecandu narkoba efektivitas rehabilitasi untuk menyembuhkan korban dari Narkoba ini sangat diperlukan(Felicia, 2015)

Rehabilitasi merupakan upaya untuk memulihkan dan mengembalikan kondisi korban dan penyalahgunaan narkoba agar kembali sehat secara fisik, psikologik, sosial dan spiritual. Dengan kondisi sehat diharapkan mereka mampu kembali berfungsi secara normal dalam kehidupan sehari-hari. Layanan rehabilitasi harus memberikan layanan yang berkualitas untuk memenuhi tujuan dari rehabilitasi tersebut. Untuk itu dibutuhkan standarisasi lembaga rehabilitasi, tenaga rehabilitasi, metode rehabilitasi, sarana dan prasarana layanan rehabilitasi pecandu dan korban penyalahgunaan narkoba.

Ketergantungan narkoba adalah suatu kondisi yang ditandai oleh dorongan untuk menggunakan narkoba secara terus menerus dengan takaran yang terus meningkat sehingga menimbulkan efek perubahan fisik dan mentalitas (fisik dan fisikis). Ketergantungan narkoba ini terutama pada zat atau obat yang berasal dari tanaman atau bukan tanaman, baik secara sintetis maupun semi sintetis yang dapat menyebabkan penurunan atau perubahan kasadaran, hilangnya rasa nyeri dan dapat merusak daya fikir dan mental.

Untuk mengurangi dan menekan peningkatan penyalahgunaan dari ketergantungan narkoba, diperlukan penanganan secara komprehensif dengan melibatkan berbagai profesi dan keahlian. Penanganan narkoba ini salah satunya dalam bentuk pemulihan dengan Pendidikan Agama khususnya Agama Islam. Menanamkan keyakinan kepada Allah SWT akan menimbulkan rasa takut dan merasa diawasi Allah SWT dalam setiap tindakan dan keadaan mereka, dan menjadi pembiasaan untuk menjalankan ibadah yang merupakan bagian dari pendidikan akhlak (Saefulloh, 2018) Namun dalam pelaksanaannya dirasakan masih belum optimal di Rumah Yayasan Rehabilitasi Rumah Ummi. Dengan membangkitkan Kesadaran beragama bagi Clien yang direhabilitasi merupakan salahsatu konseling pada hakekatnya adalah proses hubungan professional antara seorang konselor dank clien secara berkelanjutan, dengan membantu meningkatkan kesadaran akan masalah yang dialami serta potensi yang dimilikinya. Karenanya, konseling menjadi pekerjaan terpenting dalam pemulihan bagi korban penyalahgunaan narkoba.

Konseling yang diberikan kepada korban penyalahgunaan narkoba baik melalui sistem dalam institusi maupun luar institusi menjadi tantangan khusus bagi konselor. Karena pihak konselor merupakan intervensi utama atau kegiatan ini secara keseluruhan selama proses pemulihan. Untuk itulah, konselor harus mampu mengembangkan keahliannya, sensivitas dalam menganlisis masalah dan memahami individu baik yang sifatnya fisiologis, psikologis, sosial, spiritual, maupun vakasional. Hal ini dilakukan dengan mempertimbangkan aspek-aspek dalam konseling, yaitu prinsip, keterampilan, teknik, strategi, proses pelaksanaan, dan tahapan konseling, serta supervisi dalam konseling dengan membangkitkan kesadaran beragama.

Dalam kegiatan seharinya juga perlu ditekankan aspek pelaksanaan dan pengalaman keagamaan agar memperkuat benteng rohaniah para residen untuk menjawab setiap pergumulan persoalan pribadinya. Begitulah seminar-seminar juga dilakukan guna memenuhi wawasan dan khazanah residen/client sehingga mereka dapat menggunakan potensi rasa dan fikirnya untuk menganalisis setiap persoalan, terutama aspek penyalahgunaan narkoba.

Menurut Data daripada Badan Narkotika Nasional (BNN) Sumatera Utara mengemukakan bahwa Sumatera Utara merupakan Nomor satu peredaran narkoba di Indonesia.Sedangkan Kota Medan berada di urutan ketiga dari seluruh kota yang ada di Indonesia dan termasuk zona merah (ARIFIN, 2013)

Kondisi yang terjadi pada masa sekarang ini bahwa penyalahgunaan Narkoba ini sudah sangat memprihatinkan yang terjadi di Kota Medan, oleh karena itu diperlukan perhatian yang sangat serius untuk memeranginya salah satunya diperlukan suatu Pusat rehabilitasi yang secara optimal dimana eks narkoba tersebut $100 \%$ bisa melepaskan dari ketergantungan daripada barang haram tersebut. Salah satu Peneliti dr.Hari Nugroho mengemukakan bahwa proses dari rehabilitasi tersebut diperlukan tiga tahap antara lain(Purwani, Darmadi, \& Walesa, 2016): (1) Gejala penanganan putus zat atau disebut dengan detosifikasi; (2) Rehabilitasi non medis; dan, (3) After care. 
Ada juga artikel oleh pujiani dari BNN pada tanggal 05 Maret 2009, yang berjudul Terapi Narkoba dengan Sholat. Yang intinya dia melihat banyak pecandu narkoba yang gagal dalam pengobatan,ketika dibiasakan mengerjakan sholat justru ketergantungan mereka pada narkoba jadi hilang (Bakri \& Barmawi, 2017)

Berdasarkan hasil penelitian tersebut bahwa sangat diperlukan saat ini penanganan bagi pecandu narkoba dikembangkan suatu rehabilitasi yang penanganannya dilakukan secara non medis hal ini disebabkan karena penyembuhan dari pecandu narkoba ini memerlukan waktu, hal ini disebabkan karena berdampak kepada kondisi kejiwaan yang dapat menimbulkan berbagai masalah sosial hingga tindakan kriminal.menyembuhkan bagi pecandu narkoba juga menguras waktu dan tenaga oleh karena itu penyembuhan bagi pengguna narkoba ini rehabilitasi non medis dengan menggunakan metode spiritualitas dakwah keagamaan dengan membangkitkan kesadaran beragama efektif untuk menyembuhkan bagi penderita narkoba ini dengan metode antara lain: membina sholat, zikir, membaca ayat Al-Quran dll merupakan motivasi untuk penyembuhan jiwa, apabila sembuh dapat berinteraksi kembali dengan masyarakat dan lingkungannya (Hasyim Hasanah, 2015).

\section{METODE PENERAPAN}

Metode Penerapan yang dilakukan dalam kegiatan Membangkitkan Kesadaran Beragama Dalam Upaya Penyembuhan bagi penyalahgunaan Narkotika di Yayasan Rehabilitasi Rumah Ummi yang berada di Sunggal antara lain:

\section{Metode Pendidikan}

Adalah kebutuhan-kebutuhan pokoknya harus terjamin, baik kebutuhan jasmani maupun rohani serta kebutuhan psikis dan kebutuhan sosial harus terpenuhi secara maksmimal.Hal ini sebagaimana yang dikemukakan oleh Maslow dan Teori Needs yakni pemenuhan kebutuhan dasar yang sangat menunjang demi untuk perkembangan seseorang secara optimal.

\section{Pembinaan Moral}

Pembinaan moral yang paling tepat terdapat dalam Agama, maka sebenarnya Pendidikan Agama mengandung nilai-nilai moral yang perlu dilaksanakan sejak anak lahir sampai duduk di bangku sekolah dan dalam lingkungan masyarakat dimanapun berada.

\section{Pembinaan Takwa}

Penanaman jiwa takwa adalah mengendalikan kelakuan, tindakan dan sikap dalam hidup, karena mental yang sehat yang penhuh dengan keyakinan beragama adalah menjadi polisi, pengawas dari segala tindakan. Pembinaan mental pada seseorang yang direhabilitasi tidak mungkin tanpa menanamkan jiwa agama pada tiaptiap orang tersebut, karena agamalah yang memberikan kontrol dalam diri seseorang. Mental yang sehat adalah Iman.

Kegiatan Pendampingan Membangkitkan Kesadaran Beragama ini dilaksanakan dengan Praktek langsung kepada masing masing yang direhabilitasi di Rumah Ummi tersebut.

\section{HASIL DAN KETERCAPAIAN SASARAN}

Yayasan Rehabilitasi Narkoba Rumah Ummi Sejak berdiri di mulai tanggal 01 Mei 2015 di Medan, telah melakukan berbagai upaya pemulihan bagi para pecandu narkoba. Pusat rehabilitasi narkoba yang beralamat di Jl. Rajawali no 91 Medan ni, telah terdaftar di Kemenkumham RI No. AHU-0007286.AH.01.04 Tahun 2015, Dinas Sosial Tenaga Kerja No. 433.3./3140/DSTKM/2015 dengan Akte Notaris 01 tanggal 09 Mei 2015 Notaris Fenty Iska, SH di Medan.Pendirian Yayasan ini berawal daripada rendahnya kepedulian umat Islam pada korban penyalahgunaan narkoba dari 20 tempat rehabilitasi yang layak di Sumatera Utara $99 \%$ kepemilikannya adalah merupakan non Muslim.Padahal $90 \%$ korban dari penyalahgunaan narkoba tersebut adalah beragama Islam. kondisi ini dikhawatirkan akan berpengaruh pada Agama dan akidah keIslaman daripada korban Narkoba.

Yayasan Rehabilitasi Narkoba Rumah Ummi ini bertujuan melakukan kegiatan rehabilitasi serta memperbaiki mental penyalahgunaan narkoba sehingga dapat bermanfaat dan di terima masyarakat luas.

Visi Yayasan Rehabilitasi Narkoba Rumah Ummi yaitu agar dapat pulih dan diterima kembali di tengah masyarakat yang menjalani rehabilitasi tersebut. Sementara misi Yayasan ini adalah memberikan pelayanan dan kenyamanan yang terbaik dengan fasilitasi pendukung, dan membangun kembali kepercayaan diri para pelaku penyalahgunaan narkoba melalui program-program pembelajaran dengan adopsi dari program Therapeutic Community (TC), Religisdandukungan program pelatihanlainnya. 
Adapun kegiatan membangkitkan kesadaran beragama bagi resident yang dilakukan di Yayasan Rehabilitasi Rumah UMMI ini antara lain:

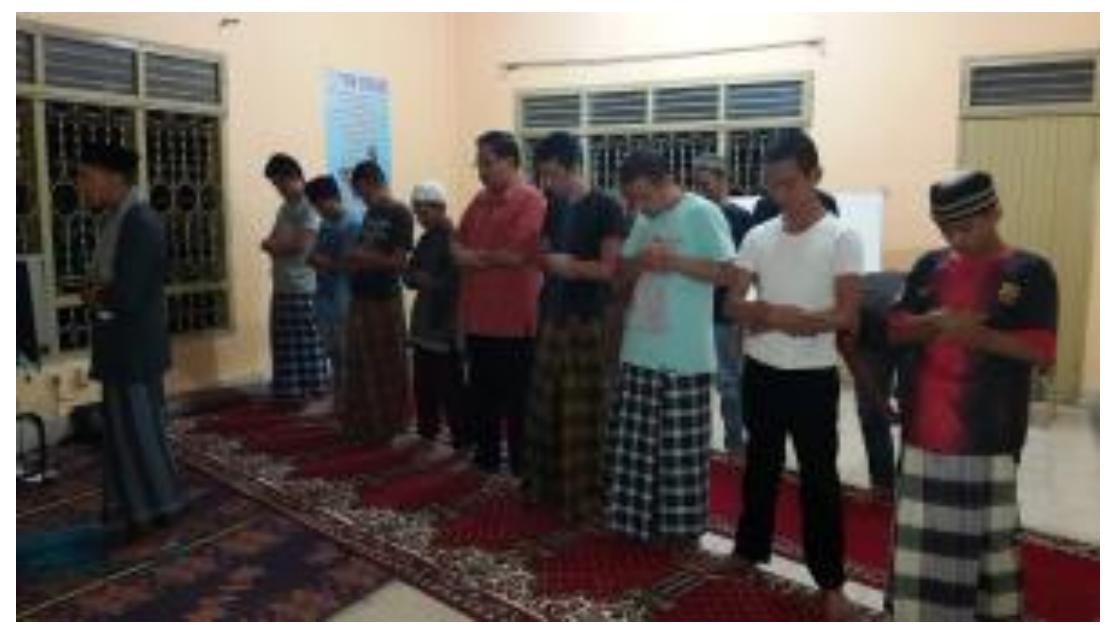

Gambar 1. Sholat Berjamaah

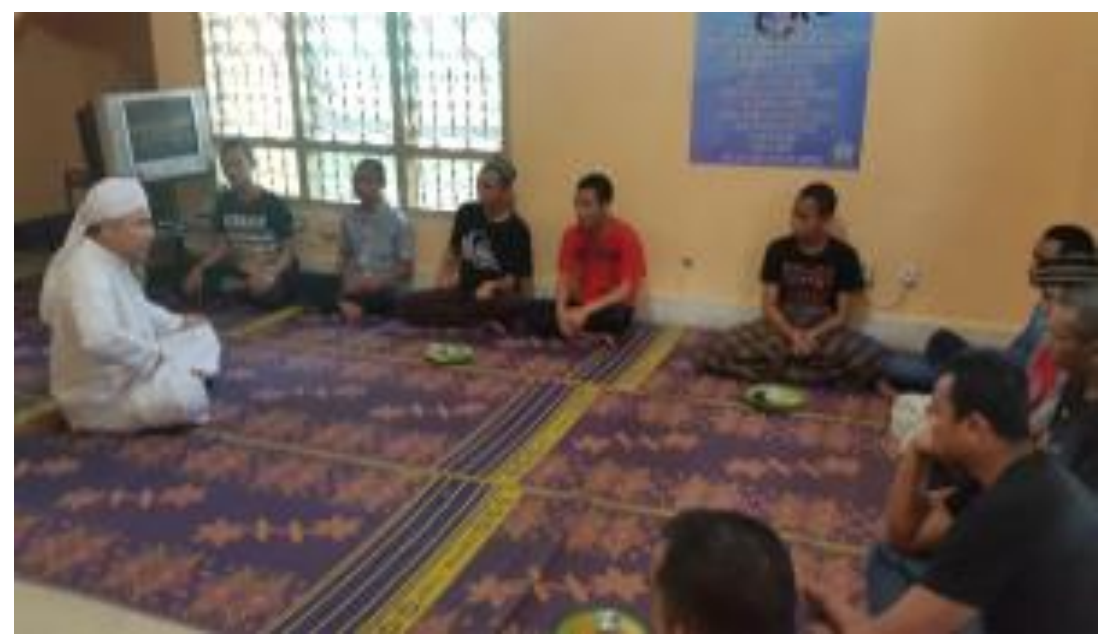

Gambar 2. Pengajian

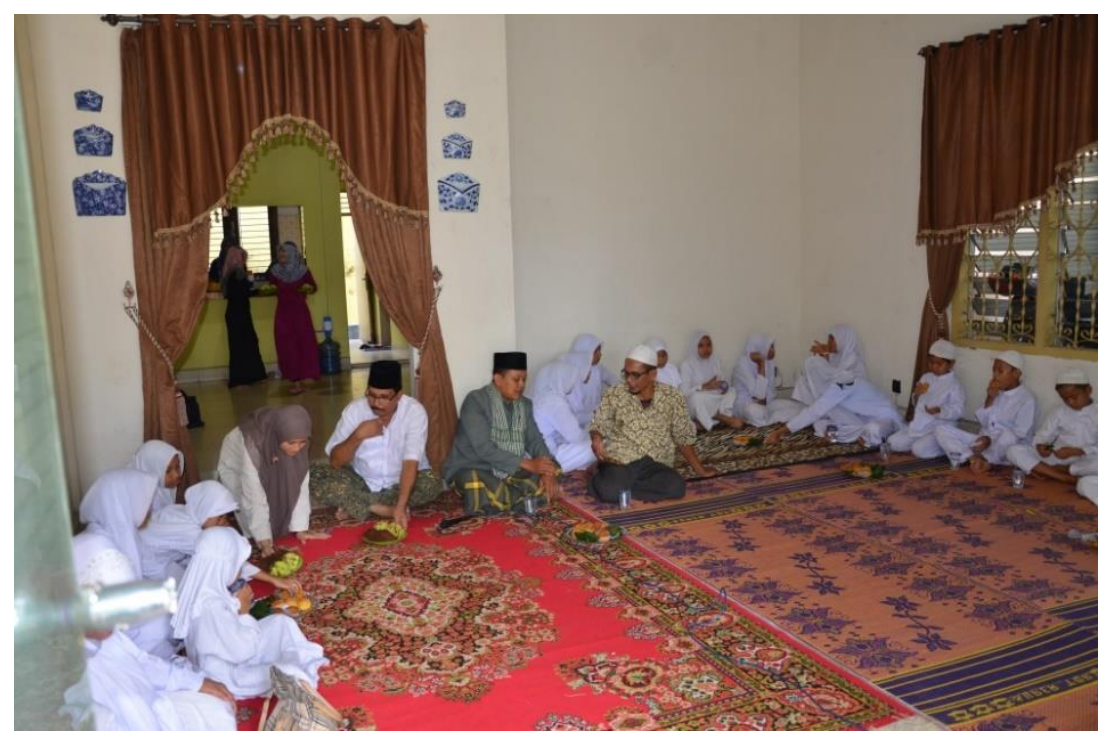

Gambar 3. Memberi Santunan Anak Yatim 
Kegiatan Pengabdian Masyarakat dari UMN Alwashliyah ini merupakan pendanaanmya berasal dari Dikti bermitra dengan Pusat Rehabilitasi Rumah Ummi ini mengembangkan Konsep Membangkitkan kesadaran Beragama dari Residen.Kesadaran adalah kondisi tau, mau dan mengerti dengan dirinya sendiri.kesadaran merupakan pemahaman secara utuh mengenai jati diri yang memberikan ruang seluas-luasnya untuk bertindak dan berperilaku sejalan dengan kemampuan dan batas-batasan yang melekat dalam diri seseorang. Salah satu bentuk kesadaran tersebut adalah dalam kaitanya dengan kesadaran beragama suatu kondisi yang mengerti, memahami, menghayati, dan melaksanakan seluruh ajaran agama secara benar dan konsisten.Membangkitkan Kesadaran Beragama adalah merupakan suatu proses daripada akumulasi daripada seluruh pengalaman hidup yang dikenali sebagai refleksi dari falsafah dan pandangan hidup, sehingga menghadirkan nilai-nilai yang positif.Nashori menyebutkan bahwa kondisi sadar sebagai proses pendewasaan hasil dari perkembangan watak keberagamaan dan dilanjutkan sebagai perjalanan spiritual. Oleh karena konsep dari Yayasan Rumah Ummi sudah merupakan konsep kesadaran Beragama yang selama ini telah mengembangkan konsep spiritual di dalam agenda rutin rehabilitasinya.kegiataan ini hanya melengkapi dari Program yang telah ada sebelumnya diantaranya: a. Belajar Praktek Sholat b. Mengadakan Seminar Kecil dan diskusi yang berkaitan dengan Tema yang aktual yang berkaitan dengan kegiatan-kegiatan keagamaan.

\section{KESIMPULAN}

Dengan Kegiatan Membangkitkan Kesadaran Beragama ini kepada Resident yang diRehabilitasi Di Rumah Ummi ini memiliki kesadaran beragama yang tinggi di dalam dirinya dan dalam aktivitas kehidupannya seharihari menghadirkan sistem nilai yang positif dengan memiliki kemampuan memahami dan menghayati ajaran agamadan memiliki kemampuan untuk merefleksikan hati nuraninya.

\section{UCAPAN TERIMA KASIH}

Kegiatan Pengabdian Kepada Masyarakat ini Merupakan Tim Dari Dosen-Dosen UMN Al - Washliyah Medan Mengucapkan Terima Kasih Yang sebesar-Besarnya Kepada KemenristekDikti Yang Telah memberikan Bantuan Dana Hibah Pengabdian Kepada Masyarakat Tahun Anggaran 2019.Semoga Dengan Adanya Kegiatan ini sangat bermanfaat bagi Dosen-dosen UMN Al Washliyah Medan untuk mengaplikasi ilmunya dan Kepada Yayasan Rehabilitasi Rumah UMMI yang terletak di Jalan Rajawali No.91 Sei Sikambing Kecamatan Medan Sunggal Sumatera Utara. mengucapkan terima kasih yang sebesar-besarnya yang bersedia menjadi Mitra sehingga terlaksananya kegiatan ini.

\section{DAFTAR PUSTAKA}

Arifin, T. N. 2013. Implementasi Rehabilitasi Pecandu Narkotika dalam Undang-Undang Republik Indonesia Nomor 35 Tahun 2009 tentang Narkotika sebagai Upaya Non Penal Badan Narkotika Nasional Artikel. Universitas Brawijaya, 2 (SGEM2016 Conference Proceedings, ISBN 978-619-7105-16-2 / ISSN 1314-2704), 1-39. Retrieved from hukum.studentjournal.ub.ac.id/index.php/hukum/article/download/45/42

Bakri, N., \& B. Barmawi. 2017. Efektifitas Rehabilitasi Pecandu Narkotika melalui Terapi Islami di Badan Narkotika Nasional (BNN) Banda Aceh. Psikoislamedia: Jurnal Psikoislamedia 2(1): 86-95. https://doi.org/10.22373/psikoislamedia.v2i1.1827

Felicia, E. 2015. Kendala dan Upaya Rehabilitasi bagi Pecandu Narkotika oleh Badan Narkotika Nasional Provinsi (BNNP) Yogyakarta. Uajy 3(2): 54-67. http://e-journal.uajy.ac.id/9034/1/JURNALHK10324.pdf

Hasanah, H. 2015. Faktor-faktor Pembentuk Kesadaran Beragama Anak Jalanan. SAWWA 10 (April): 209-227. journal.walisongo.ac.id/index.php/sawwa/article/download/1432/1051\%0A\%0A

Purwani, S. P. M. E., Darmadi, \& I. M. Walesa. 2016. Implementasi Pengaturan Rehabilitasi Penyalah Guna Narkotika Oleh Badan Narkotika Nasional Kota Denpasar. Kertha Patrika 38(Januari-April): 62-83. https://ojs.unud.ac.id/index.php/kerthapatrika/article/download/21535/14234

Saefulloh, A. 2018. Rehabilitasi Eks-Pecandu Narkoba Melalui Pendekatan Agama Islam. ISLAMIC COUNSELING: Jurnal Bimbingan Konseling Islam 2(1): 43. https://doi.org/10.29240/jbk.v2i1.377 